\title{
Cryogenic superelasticity with large elastocaloric effect
}

\author{
Kodai Niitsu, Yuta Kimura, Toshihiro Omori and Ryosuke Kainuma
}

Shape-memory alloys suitable for low-temperature environments are crucially lacking despite their potential applications for aerospace engineering, superconducting technologies, and liquefied-gas-storage technologies. Even for benchmark shape-memory alloys such as $\mathrm{Ti}-\mathrm{Ni}$ and $\mathrm{Ni}$-based Heusler alloys, superelasticity becomes appreciably difficult to achieve upon cooling because of a drastic increase in stress hysteresis. Here, we report a superelastic strain of more than $7 \%$ for a $\mathrm{Cu}-\mathrm{Al}-\mathrm{Mn}$ shape-memory alloy down to $4.2 \mathrm{~K}$ with stress hysteresis as small as that at ambient temperature. Furthermore, the transformation entropy change remains as large as that at ambient temperature down to $\sim 50 \mathrm{~K}$. Consequently, an excellent elastocaloric cooling property is simultaneously obtained even at cryogenic temperatures, at which existing shape-memory alloys lose this property because of decreased entropy change and increased stress hysteresis. The developed cryogenic superelastic alloy shows excellent potential as a new class of material combining superelastic properties with sufficiently small dissipated energy and persistent elastocaloric cooling ability even in cryogenic environments.

NPG Asia Materials (2018) 10, e457; doi:10.1038/am.2017.213; published online 5 January 2018

\section{INTRODUCTION}

Shape-memory alloys (SMAs) are alloys that undergo the diffusionless solid-solid phase transformation known as martensitic transformation (MT). Their functionalities-the shape-memory effect and superelasticity-have long stimulated considerable interest in the field of materials science and engineering. The superelasticity enables a large recoverable strain to be attained using the stress-induced forward/ reverse MTs via the application/release of uniaxial stress. ${ }^{1}$ The behavior is similar to that of elastomers; the stress-strain $(\sigma-\varepsilon)$ curve exhibits plateaus but not linearity as a superelastic response. ${ }^{1}$ This functionality has resulted in many important applications, such as guide wires and damping components. ${ }^{1-3}$ In addition, refrigeration using the latent heat yielded by the stress-induced MT has recently received considerable attention as an environmentally friendly refrigeration technique called elastocaloric cooling (EC) ${ }^{4}$ which may be a promising alternative to conventional vapor-compression techniques. This EC effect (previously termed the piezocaloric effect ${ }^{5}$ ) exploits the transformation entropy change $\Delta S$ as a cooling source under adiabatic conditions. $\Delta S$ is related to the equilibrium stress $\sigma_{0}$ and transformation strain $\varepsilon_{\mathrm{SE}}$ by the Clausius-Clapeyron equation: ${ }^{6}$

$$
\frac{\mathrm{d} \sigma_{0}}{\mathrm{~d} T}=-\frac{\Delta S}{\varepsilon_{\mathrm{SE}} \times V_{\mathrm{m}}}
$$

where $V_{\mathrm{m}}$ represents molar volume. Therefore, investigating the temperature dependence of superelastic behaviors can be used as an indirect approach to evaluate the EC potential of SMAs.

In the design of practical SMAs, minimizing the transformation hysteresis without deteriorating the shape-memory and/or superelastic property is a general strategy because it leads to reproducibility of these functionalities and enhancement of their fatigue properties. ${ }^{7}$
However, simultaneously achieving small $\sigma_{\text {hys }}$ and large $\varepsilon_{\mathrm{SE}}$ (or $\Delta S$ ) remains challenging. Even for the $R$-phase (trigonal-symmetric martensite) transformation in $\mathrm{Ti}-\mathrm{Ni}$, which exhibits a small temperature hysteresis of less than a few degrees Kelvin, the obtainable $\varepsilon_{\mathrm{SE}}$ is $<1 \%{ }^{8}$ therefore, $\Delta S$ is also small. In contrast, $\sigma_{\text {hys }}$ in SMAs with large $\varepsilon_{\mathrm{SE}}$, for example, in FeNiCoAlTaB, ${ }^{9}$ is generally large. Recently, an extremely small temperature hysteresis and thereby excellent fatigue properties were achieved in certain SMAs ${ }^{10-12}$ because of the very small lattice mismatch between the parent and martensite phases $^{10,11}$ or among them and precipitates ${ }^{12}$ arising from special relationships intrinsic to their lattice correspondence $e^{10-13}$ (termed 'supercompatibility' by James ${ }^{14}$ ). Another, more conventional approach involves tailoring the microstructure to reduce intergranular constraints; the fatigue properties of $\mathrm{Cu}-\mathrm{Al}-\mathrm{Mn} \mathrm{SMA}$ in the forms of a single crystal, bamboo-like polycrystals, and columnar-oriented polycrystals have been successfully improved while realizing small $\sigma_{\text {hys }}$ and large $\varepsilon_{\mathrm{SE}} \cdot{ }^{15,16}$

Attempts to widen the SMA working temperature window have been mainly focused on the high-temperature direction, ${ }^{17}$ and few have been reported for the low-temperature direction. The shape-memory effect at $4.2 \mathrm{~K}$ was demonstrated by Nikolaev et al. ${ }^{18}$ in a $\mathrm{Cu}-\mathrm{Al}-\mathrm{Ni} \mathrm{SMA}$, and superelasticity below $77 \mathrm{~K}$ has been confirmed by the present group in $\mathrm{Ti}-\mathrm{Ni}^{19,20}$ and $\mathrm{Ni}-\mathrm{Co}-\mathrm{Mn}-\mathrm{In}$ alloys. $^{21}$ In these alloys, however, as shown in Figure 1a and b, $\sigma_{\text {hys }}$ markedly increases at decreased temperatures, which makes the operation of superelasticity difficult and further induces serrated flow in superelasticity at cryogenic temperatures. ${ }^{20,21}$ In general, the intrinsic mechanical properties of materials dramatically change in low-temperature environments. For example, polymers generally lose their excellent elasticity below their glass transition temperatures 


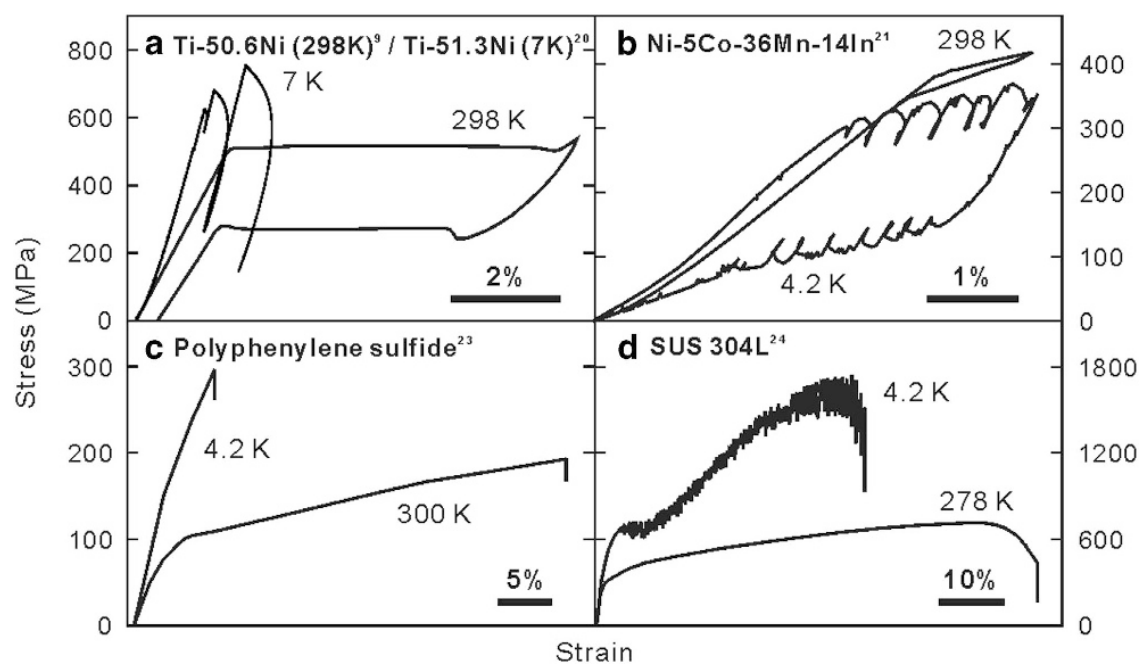

Figure 1 Mechanical properties of materials at cryogenic and ambient temperatures. (a) Ti-50.6Ni alloy at $298 \mathrm{~K}^{9}$ and Ti-51.3Ni alloy at $7 \mathrm{~K}{ }^{20}$ (b) Ni-5Co$36 \mathrm{Mn}-14$ In Heusler alloy. ${ }^{21}$ (c) Polyphenylene sulfide. ${ }^{23}$ (d) SUS 304L. ${ }^{24}$

(Figure 1c), 22,23 and many metals become brittle because of an increase in proof stress and further exhibit serrated deformations (particularly below $\sim 30 \mathrm{~K}$ ) (Figure $1 \mathrm{~d}),{ }^{24}$ resulting in the generation of local heating of up to $\sim 100 \mathrm{~K} .{ }^{25}$ Low-temperature-operable superelastic alloys with large recoverable strain, hereafter called cryogenic superelastic alloys, will have significant engineering impact as a new class of cryogenic materials.

Here, we report that single-crystalline $\mathrm{Cu}-17 \mathrm{Al}-15 \mathrm{Mn}$ (at.\%) can exhibit $\varepsilon_{\mathrm{SE}}>7 \%$ at $4.2 \mathrm{~K}$ while keeping $\sigma_{\text {hys }}<\sim 30 \mathrm{MPa}$. The $\Delta S$ is sustained down to approximately $50 \mathrm{~K}$, which is as large as that at ambient temperature. These properties are promising for practical applications as cryogenic superelastic alloys as well as EC devices.

\section{MATERIALS AND METHODS}

Ingots of $\mathrm{Cu}-17 \mathrm{Al}-15 \mathrm{Mn}$ and $\mathrm{Cu}-17 \mathrm{Al}-12 \mathrm{Mn}$ (at.\%) were prepared by induction melting in an Ar atmosphere. The ingots were hot-rolled at $1143 \mathrm{~K}$ to reduce their thickness to $\sim 3 \mathrm{~mm}$. The obtained plates were subjected to cyclic heat treatment (see Supplementary Figure S1a) to obtain single crystals by inducing abnormal grain growth. ${ }^{26}$ The plates (shown in Supplementary Figure S1b) were subsequently annealed at $473 \mathrm{~K}$ for $15 \mathrm{~min}$ to stabilize the MT behavior between the cubic $\left(L 2_{1}\right)$ parent and monoclinic (18R, now often termed 6M) martensite phases. ${ }^{27,28}$ As shown in Supplementary Figure S2, it was confirmed that the obtained $\mathrm{Cu}-17 \mathrm{Al}-15 \mathrm{Mn}$ does not undergo the thermally induced MTs in the temperature range $4-300 \mathrm{~K}$.

A series of tensile tests of $\mathrm{Cu}-17 \mathrm{Al}-15 \mathrm{Mn}$ single crystals was performed at a strain rate of $5 \times 10^{-5} \mathrm{~s}^{-1}$ in order from the highest to lowest test temperatures. To account for the training effect, the tests were conducted at least twice at every temperature, and the $\sigma-\varepsilon$ curve obtained in the final test was used. The tensile orientations in the tested single crystals were determined using the electron backscattered diffraction technique.

\section{RESULTS AND DISCUSSION}

The tensile $\sigma-\varepsilon$ curves of the $\mathrm{Cu}-\mathrm{Al}-\mathrm{Mn}$ single-crystal specimen (\#1) in the low-strain region at temperatures of $4.2-160 \mathrm{~K}$ are presented in Figure 2. The series of $\sigma-\varepsilon$ curves indicates that the superelastic property was successfully achieved at all the temperatures tested. The two insets show the full superelastic curve at $4.2 \mathrm{~K}$ and the crystallographic orientation of the tested crystal on an inverse pole figure. Those for another crystal (\#2) with a different orientation are provided in Supplementary Figure S3. The $\varepsilon_{\mathrm{SE}}$ values of $7.1 \%$ and $5.3 \%$ for specimens $\# 1$ and $\# 2$ at $4.2 \mathrm{~K}$ are less than the theoretical values of
9.1\% and 7.6\%, respectively, estimated from the crystallographic relationship between the cubic $\left(L 2_{1}\right)$ parent and monoclinic (18R) martensite phases in a $\mathrm{Cu}-17 \mathrm{Al}-10 \mathrm{Mn}$ SMA at ambient temperature. ${ }^{29}$ This discrepancy may have been caused by a change in the lattice parameters resulting from the different $\mathrm{Mn}$ concentration and temperature. The critical stresses, $\sigma_{\mathrm{Ms}}$ and $\sigma_{\mathrm{Af}}$, of the stressinduced forward/reverse MTs, as depicted in Figure 2, are plotted in Figure $3 \mathrm{a}$ as a function of temperature. Those reported for bamboo-textured ${ }^{30}$ and columnar-grained ${ }^{31} \mathrm{Cu}-\mathrm{Al}-\mathrm{Mn}, \mathrm{Ti}-\mathrm{Ni},{ }^{19}$ and $\mathrm{Ni}-\mathrm{Co}-\mathrm{Mn}-\mathrm{In}^{21}$ are also plotted, and $\sigma_{0}$, which is approximated by $\left(\sigma_{\mathrm{Ms}}+\sigma_{\mathrm{Af}}\right) / 2$, is represented by the broken lines. In contrast to $\mathrm{Ti}-\mathrm{Ni}$ and $\mathrm{Ni}-\mathrm{Co}-\mathrm{Mn}-\mathrm{In}$, the $\sigma_{\mathrm{hys}}\left(=\sigma_{\mathrm{Ms}}-\sigma_{\mathrm{Af}}\right)$ values of which increase upon cooling, $\mathrm{Cu}-\mathrm{Al}-\mathrm{Mn}$ shows a nearly constant $\sigma_{\text {hys }}$ down to $4.2 \mathrm{~K}$, as clearly shown in Figure $3 \mathrm{~b}$. The dramatic increase in $\sigma_{\text {hys }}$ for $\mathrm{Ti}-\mathrm{Ni}$ and $\mathrm{Ni}-\mathrm{Co}-\mathrm{Mn}-\mathrm{In}$ has been believed to be caused by the development of the thermal activation of the habit plane (phase boundary between the parent and martensite phases) motion; ${ }^{19,21}$ therefore, the superelasticity in $\mathrm{Cu}-\mathrm{Al}-\mathrm{Mn}$ is deduced to dominantly occur athermally. The $\Delta S$ values derived from Equation (1) using $V_{\mathrm{m}}=7.59 \times 10^{-6} \mathrm{~m}^{3} \mathrm{~mol}^{-130}$ are plotted in Figure $3 \mathrm{c}$ alongside those measured using differential scanning calorimetry for thermally induced MTs. ${ }^{31-33}$ Note that among the $\Delta S$ curves drawn with solid lines, that for $\mathrm{Cu}-\mathrm{Al}-\mathrm{Mn}$ was directly derived from the specific heat measurements for the parent and martensite phases (Supplementary Figure $\mathrm{S} 4 \mathrm{a}$ and $\mathrm{b}$ ), whereas those for $\mathrm{Ti}-\mathrm{Ni}$ and $\mathrm{Ni}-\mathrm{Co}-\mathrm{Mn}$-In were derived from the superelastic behaviors provided in the literature. ${ }^{19-21}$ For $\Delta S$ of $\mathrm{Cu}-\mathrm{Al}-\mathrm{Mn}$, it is apparent that the superelastic behavior successfully follows that expected from the specific heat of the parent and martensite phases. In particular, $\Delta S$ of $\mathrm{Cu}-\mathrm{Al}-\mathrm{Mn}$ remained as large as that at ambient temperature down to $\sim 50 \mathrm{~K}$, while those of the Ti-Ni and Ni-Co-Mn-In alloys decreased monotonically during cooling.

The demonstrated superelastic behaviors of $\mathrm{Cu}-\mathrm{Al}-\mathrm{Mn}$ highlight the unique potential of this alloy as a cryogenic superelastic alloy in terms of the two above-mentioned requirements: small $\sigma_{\text {hys }}$ and large $\varepsilon_{\mathrm{SE}}$. Moreover, the potential of a cryogenic superelastic alloy should be assessed according to another aspect of the EC property. The EC property can be quantitatively evaluated based on two factors: the latent heat of the one-way (forward or reverse) MT (Q) and the concomitant dissipated energy caused by the friction against 


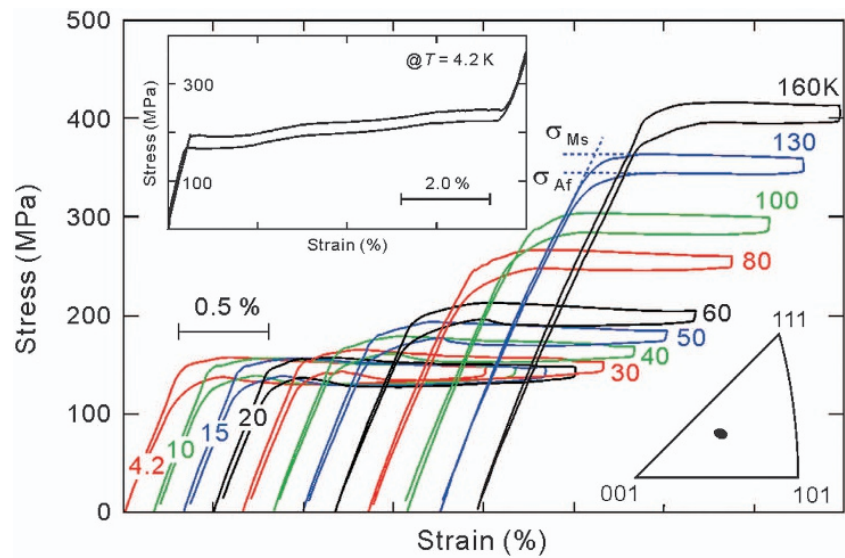

Figure 2 Tensile $\sigma-\varepsilon$ curves for $\mathrm{Cu}-17 \mathrm{Al}-15 \mathrm{Mn}$ single crystal \#1 with initial superelastic plateaus of $\sim 1.5 \%$ at various temperatures ranging from 4.2 to $160 \mathrm{~K}$. The critical stresses, $\sigma_{\mathrm{Ms}}$ and $\sigma_{\mathrm{Af}}$, of the stress-induced forward/ reverse MTs are defined as the intersections of the lines extrapolated from the elastic curve and forward/reverse superelastic plateaus, respectively. The upper inset presents the tensile $\sigma-\varepsilon$ curve, showing full superelasticity at $4.2 \mathrm{~K}$. The crystallographic orientation of this crystal in the tensile direction is shown in the inverse pole figure in the lower inset.

the motion of habit planes $(W)$, where the value of $W$ is identical to half of the area surrounded by the hysteretic superelastic loop. These factors are defined as follows:

$$
\begin{aligned}
& Q=T \times \Delta S \\
& W=\oint \sigma d \varepsilon / 2 \rho \cong \sigma_{\mathrm{hys}} \times \varepsilon_{\mathrm{SE}} / 2 \rho
\end{aligned}
$$

Here, the mass density $\rho$ of $\mathrm{Cu}-17 \mathrm{Al}-15 \mathrm{Mn}$ was estimated to be $7.38 \times 10^{3} \mathrm{~kg} / \mathrm{m}^{3}$ with the lattice constant of the cubic $\left(L 2_{1}\right)$ phase of $0.5864 \mathrm{~nm}$ for $\mathrm{Cu}-17 \mathrm{Al}-10 \mathrm{Mn} .^{29}$ The conjugated temperature changes $\Delta T_{\mathrm{ad}}$ id and $\Delta T_{\text {fri }}$ are simply represented by the isobaric specific heat $c_{\mathrm{P}}$ as

$$
\Delta T_{\mathrm{ad}}^{\mathrm{id}}=Q / c_{P}
$$

and

$$
\Delta T_{\text {fri }}=W / c_{P},
$$

respectively. $\Delta T_{\mathrm{ad}}$ id is identical to the ideal adiabatic temperature change, which does not consider the effect of $\Delta T_{\text {fri }}$. The contribution of $\Delta T_{\text {fri }}$ should be considered in evaluating the effective EC performance; the effective adiabatic temperature change $\Delta T_{\mathrm{ad}}$ eff can be determined as follows:

$$
\Delta T_{\mathrm{ad}}^{\mathrm{eff}}=\Delta T_{\mathrm{ad}}^{\mathrm{id}}+\Delta T_{\text {fri }} .
$$

The superelasticity operating near and above ambient temperature generally only exhibits a few percent contribution of $\Delta T_{\text {fri }}$ compared with that of $\Delta T_{\mathrm{ad}}$ id. Even for the ferrous polycrystalline superelastic alloy with relatively large $\varepsilon_{\mathrm{SE}}$ and $\sigma_{\mathrm{hys}},{ }^{34}$ for example, $\Delta T_{\text {fri }}$ does not exceed $3 \mathrm{~K}$ at $293 \mathrm{~K}$; therefore, little attention has been paid to the effect of the friction heat. Unlike in these cases, special attention must be paid to the balance of $\Delta T_{\text {fri }}$ and $\Delta T_{\mathrm{ad}}$ id for cryogenic superelasticity. Figure 4a presents the temperature dependences of $-Q$ and $W$ for the Cu-based ${ }^{1,30,31,35-37}$ (for calculated values, see Supplementary Figure S4c), Ti-Ni-based, and Ni-based Heusler SMAs (for concrete plots, see Supplementary Figure S5a). The crossover temperatures $T_{\mathrm{CO}}$ between $-Q$ and $W$, denoted by arrows, represent the critical temperatures at which the EC effect disappears; that is, the heat

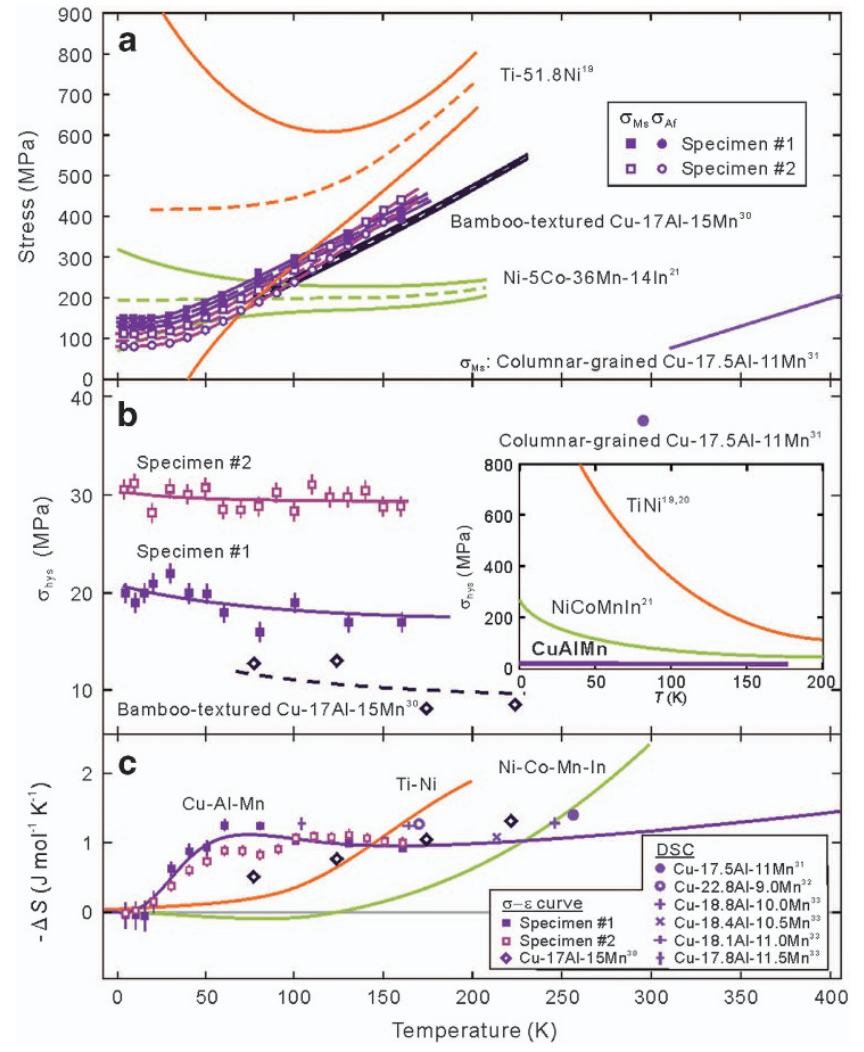

Figure 3 Temperature variation of mechanical properties of the $\mathrm{Cu}-17 \mathrm{Al}-15 \mathrm{Mn}$ single crystals in relation to the superelasticity, with reference data for other $\mathrm{Cu}-\mathrm{Al}-\mathrm{Mn} \mathrm{SMAs}^{30-33}$ and two benchmark SMAs of $\mathrm{Ti}-\mathrm{Ni}^{19,20}$ and $\mathrm{Ni}-\mathrm{Co}-\mathrm{Mn}-\mathrm{In} .^{21}$ (a) Critical stresses, $\sigma_{\mathrm{Ms}}$ and $\sigma_{\mathrm{Af}}$, which are defined as in Figure 2. (b) Stress hysteresis $\sigma_{\text {hys. }}$ (c) Entropy change $\Delta S$. In $\mathrm{a}$, the temperature dependences of $\sigma_{\mathrm{Af}}$ and $\sigma_{0}$ for the columnar-grained $\mathrm{Cu}-17 \mathrm{Al}-11.5 \mathrm{Mn}$ have not been evaluated. ${ }^{31}$ In $\mathrm{c}$, the solid $\Delta S$ curves for $\mathrm{Cu}-\mathrm{Al}-\mathrm{Mn}$ were derived from the specific heat measurements for the parent and martensite phases (Supplementary Figure S4b).

balance in the reverse MT changes from endothermal to exothermal. The present $\mathrm{Cu}-\mathrm{Al}-\mathrm{Mn}$ exhibited a significantly lower $T_{\mathrm{CO}}(\sim 22 \mathrm{~K})$ than those in the reference Ti-Ni-based $(\sim 105 \mathrm{~K})$ and Ni-based Heusler $(\sim 130 \mathrm{~K})$ systems. Although the $\mathrm{Q}$ of $\mathrm{Cu}-\mathrm{Al}-\mathrm{Mn}$ exhibits a similar tendency to that of the other SMAs, the increase of $W$ is greatly suppressed down to $4.2 \mathrm{~K}$, enabling this alloy to exhibit a persistent EC effect down to such a very low temperature.

One of the most striking indices of EC performance is the adiabatic temperature change. The temperature dependences of $\Delta T_{\mathrm{ad}}$ id and $\Delta T_{\mathrm{ad}}{ }^{\text {eff }}$ are shown in Figure $4 \mathrm{~b}$ and $\mathrm{c},{ }^{1,30,31,35-37}$ respectively, wherein negative signs are appended to the vertical axes to visualize the magnitudes of EC abilities as positive values (see Supplementary Figure S5b and c for concrete plots and Supplementary Figure S4d for the calculated values for $\mathrm{Cu}-\mathrm{Al}-\mathrm{Mn}$ ). The temperature changes experimentally measured under near-adiabatic conditions $\left(\Delta T_{\mathrm{ad}}\right)$ in a $\mathrm{Cu}-17.5 \mathrm{Al}-11 \mathrm{Mn}$ alloy are also presented, as cross marks, in Figure $4 \mathrm{c}^{31}$ The $\Delta T_{\text {ad }}$ value at $\sim 300 \mathrm{~K}$ is in good agreement with the present results, but is nearly constant even at higher temperatures. This disagreement in the temperature dependence may have been caused by the incomplete stress-induced MT at higher temperatures in the reference study ${ }^{31}$ because a constant total strain of $10 \%$ was applied in all the measurements. Because of its characteristic $\Delta S$ (Figure 3c; Supplementary Figure S4b), Cu-Al-Mn maintains a large value of $-\Delta T_{\mathrm{ad}}$ id down to the temperature region of $\sim 30 \mathrm{~K}$ and finally 

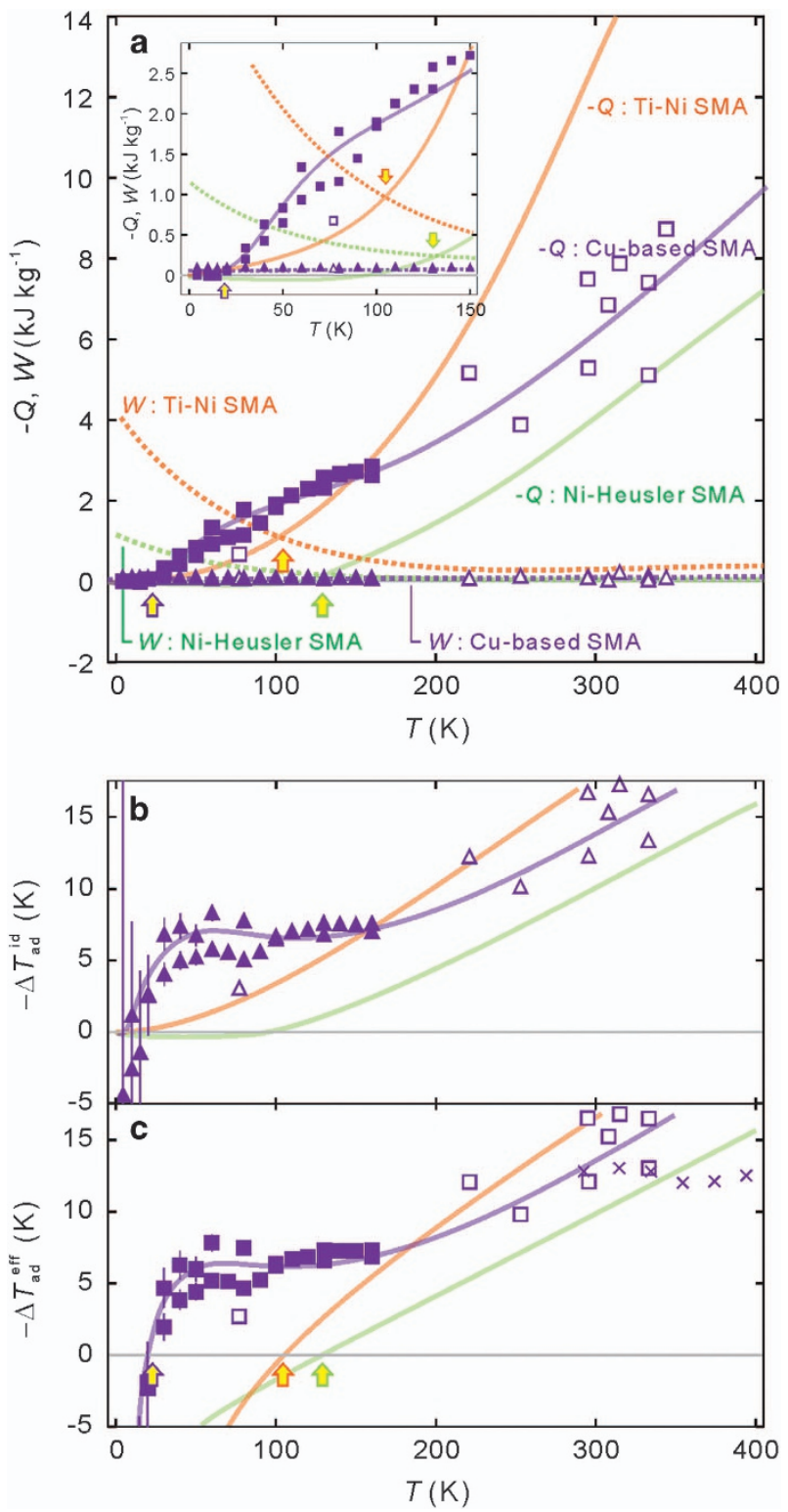

Figure 4 Temperature variation of caloric properties, with reference data for Ti-Ni-based and Ni-based Heusler SMA systems. The present data are indicated by filled symbols, whereas the reference data for the $\mathrm{Cu}$-based SMAs, including CuZnAl, CuZnSn, and CuAINi, are indicated by unfilled symbols. 1,30,31,35-37 Concrete plots and references for other SMAs are presented in Supplementary Figure S5. (a) Latent heat $-Q$ and friction heat $W$. (Inset) Magnification of the low-temperature section. (b) Ideal cooling ability $\left(-\Delta T_{\mathrm{ad}}{ }^{\mathrm{id}}\right)$ for isothermal conditions without consideration of the contribution of $W$. (c) Effective cooling ability $\left(-\Delta T_{a d}{ }^{\text {eff }}\right)$ for isothermal conditions with consideration of the contribution of $W$. The experimental adiabatic temperature change $\left(-\Delta T_{\mathrm{ad}}\right)$ is indicated by cross marks in c. ${ }^{31}$ The arrows in a indicate the crossover temperatures $\left(T_{\mathrm{CO} O}\right)$ of $-Q$ and $W$, which are identical to the temperatures at which $-\Delta T_{\mathrm{ad}}{ }^{\text {eff }}$ crosses zero in $\mathbf{c}$. In these figures, the curves for Cu-based SMA were derived from the specific heat measurements for $\mathrm{Cu}-\mathrm{Al}-\mathrm{Mn}$ (Supplementary Figure $\mathrm{S} 4 \mathrm{c}$ and $\mathrm{d}$; Supplementary Information), and those for $\mathrm{Ti}-\mathrm{Ni}$ and $\mathrm{Ni}$-based Heusler SMAs serve as guides to the reference data.

converges to zero such as that of the other SMAs. Once the contribution of $\Delta T_{\text {fri }}$ is considered, $-\Delta T_{\text {ad }}$ eff commonly decays toward negative infinity, as shown in Figure $4 \mathrm{c}$, as $c_{\mathrm{P}}$ approaches zero. For example, $\Delta T_{\text {fri }}$ at $10 \mathrm{~K}$ reached 28,635 , and $1482 \mathrm{~K}$ for $\mathrm{Cu}-\mathrm{Al}-\mathrm{Mn}$,

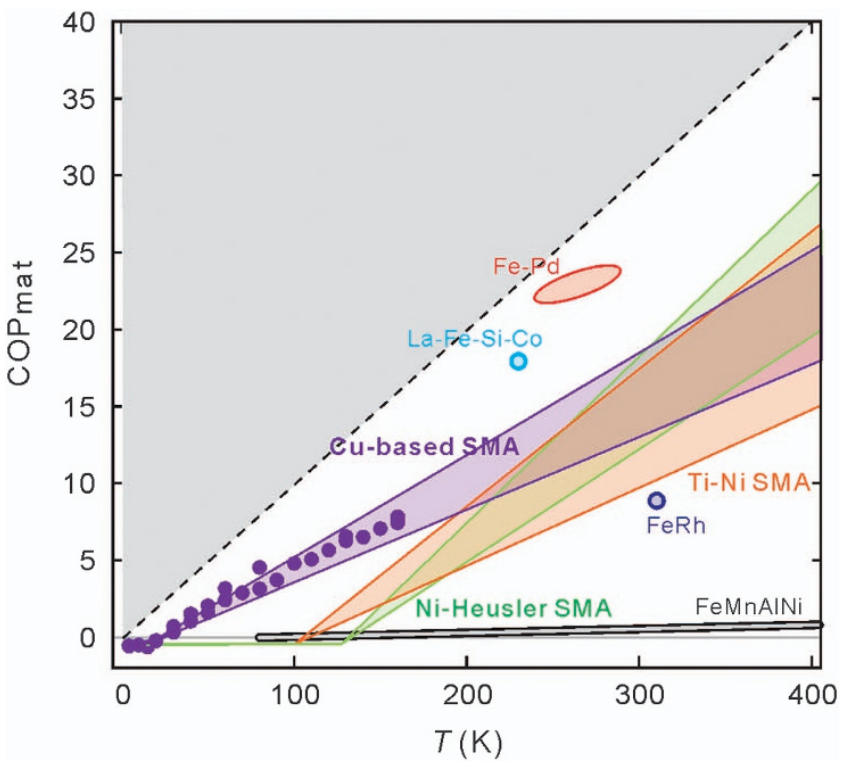

Figure $5 \mathrm{COP}_{\text {mat }}$ of various caloric materials. At an ideal condition of $W=0$, $C O P_{\text {mat }}$ falls on the dashed line of $T / \Delta T_{\text {lift, }}$, being identical to the theoretical Carnot cycle COP. In contrast, as $W$ increases, $C O P_{\text {mat }}$ deviates from $T / \Delta T_{\text {lift }}$ and approaches -0.5 . The plots for the Cu-based SMA reflect the present data. Concrete values for the other materials are presented in Supplementary Figure S6.

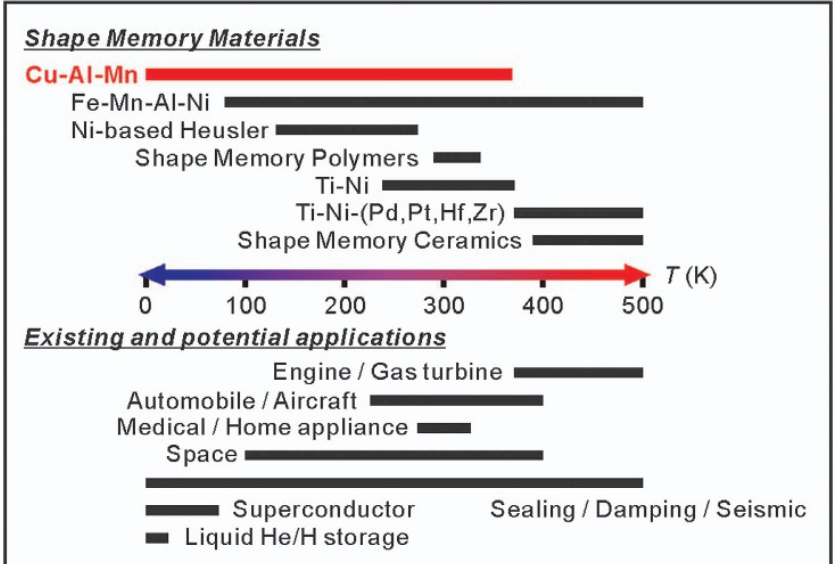

Figure 6 Existing and potential application fields and operational temperature windows of shape-memory materials.

$\mathrm{Ni}-\mathrm{Co}-\mathrm{Mn}-\mathrm{In}$, and $\mathrm{Ti}-\mathrm{Ni}$, respectively. Therefore, an attempt to expand the EC application temperature window downward unavoidably results in increasing $\Delta T_{\text {fri }}$, which can be mostly neglected at ambient temperature. Similarly to the local heating observed during plastic deformation, ${ }^{38} \Delta T_{\text {fri }}$ should invoke local heating near the migrating habit plane, which might result in the serrated behaviors clearly observed in Ti-51.3Ni at $7 \mathrm{~K}$ (see Figure $1 \mathrm{a})^{20}$ and $\mathrm{Ni}-5 \mathrm{Co}-36 \mathrm{Mn}-14 \mathrm{In}$ below $10 \mathrm{~K}$ (Figure 1b). ${ }^{21}$ Therefore, an increase in $\sigma_{\text {hys }}$ at cryogenic temperatures results in the destructive drawbacks of not only an amplification of $\Delta T_{\text {fri }}$ but also a serrated flow of superelasticity.

As previously demonstrated, the contribution of $W$ significantly changes with temperature. To quantify the EC performance of SMAs while accounting for $W$, the following index of the material-based 
coefficient of performance $\left(\mathrm{COP}_{\text {mat }}\right)$ for isothermal conditions ${ }^{39}$ was used:

$$
\mathrm{COP}_{\text {mat }}=\frac{-T \times \Delta S-W}{-\Delta T_{\text {lift }} \times \Delta S+2 W},
$$

where $\Delta T_{\text {lift }}$ is the system temperature lift and represents the difference between the heat rejection temperature (outdoor unit) and operating temperature $(T)$. Figure 5 plots the $\mathrm{COP}_{\text {mat }}$ of various reported caloric materials as a function of temperature with $\Delta T_{\text {lift }}=10 \mathrm{~K}$ (for details, see Supplementary Figure S6). Compared with other studied caloric materials, $\mathrm{Cu}-\mathrm{Al}-\mathrm{Mn}$ exhibits a relatively high $\mathrm{COP}_{\text {mat }}$ over a wide temperature range and, in particular, exhibits the highest value below $\sim 200 \mathrm{~K}$ (for the calculated value, see Supplementary Figure S4e). The lowest operating temperature reported for EC materials is $210 \mathrm{~K}$ for $\mathrm{Cu}-16 \mathrm{Al}-16 \mathrm{Zn}$, the $\Delta T_{\mathrm{ad}}$ of which is $4.2 \mathrm{~K}^{35}$ The present $\mathrm{Cu}-\mathrm{Al}-\mathrm{Mn}$ expands the temperature region over which it is implementable as an EC device downward by $\sim 190 \mathrm{~K}$. One would expect that the $\mathrm{COP}_{\text {mat }}$ values would change with the material microstructure. The microstructure generally affects the magnitude of $\sigma_{\text {hys }}$ in response to the degree of unfavorable grain constraints. Simultaneously, these constraints also deteriorate $\varepsilon_{\mathrm{SE}}$ such that $W$ becomes balanced. Indeed, the $\mathrm{COP}_{\text {mat }}$ of the three $\mathrm{Cu}-\mathrm{Al}-\mathrm{Mn}$ alloys with different microstructures and the transform temperatures showed little deviation from a linear relationship.

This cryogenic superelastic alloy has great potential for cryogenic applications, not only for use in pressure valves, sealing materials, and damping components but also in microcooling components for EC applications. The present $\mathrm{Cu}-\mathrm{Al}-\mathrm{Mn}$ is composed of inexpensive raw materials and, more importantly, has many unique advantages, including high ductility, ${ }^{27}$ high machinability, ${ }^{27}$ improved fatigue life, ${ }^{16}$ grain size tunability, ${ }^{26}$ and transformation temperature tunability. ${ }^{28}$ It has been reported that the near $\left.<100\right\rangle$-oriented single crystal exhibits very large $\varepsilon_{\mathrm{SE}}$ approaching $10 \% .{ }^{31}$ If we assume $\varepsilon_{\mathrm{SE}}=10 \%, \sigma_{\mathrm{Ms}}=50 \mathrm{MPa}$ at $4.2 \mathrm{~K}$, temperature-independent $\sigma_{\mathrm{hys}}=20$ $\mathrm{MPa}$, and critical slip stress $=500 \mathrm{MPa}$ in the near $<100>$-oriented single crystal, operations of superelasticity at temperatures up to $366 \mathrm{~K}$ and of the EC effect at temperatures as low as $T_{\mathrm{CO}}=24 \mathrm{~K}$ may be feasible; one specimen can exhibit both superelasticity and the EC effect over a wide temperature window of $\sim 340 \mathrm{~K}$. As previously mentioned, the crystallographic compatibility between the parent and martensite phases ${ }^{10-13}$ was considered to be a factor determining the magnitude of the MT temperature hysteresis. Although experimental investigations have not been attempted, this guidance appears to be valid for suppressing $\sigma_{\text {hys }}$ and temperature hysteresis; thus, the existing $\mathrm{COP}_{\text {mat }}$ metrics (Figure 5) may be revised for such supercompatible superelastic alloys. However, it is concerning that these conditions can be easily disrupted by changing temperature and composition. It remains unknown how thermal activation develops as temperature decreases because the extremely small hystereses are all observed at ambient temperatures at which the athermal nature is dominant. Therefore, the novel feature of the present $\mathrm{Cu}-\mathrm{Al}-\mathrm{Mn}$ alloy, namely, the temperature-independent small $\sigma_{\text {hys }}$ and persistent EC performance over a very wide temperature range, will not be lost even after the supercompatible strategy is applied to design a superelastic alloy.

As shown in Figure 6, the present $\mathrm{Cu}-\mathrm{Al}-\mathrm{Mn}$ alloy exclusively covers the application fields of space engineering, superconducting technologies, and liquefied-gas technologies, for which it has been almost impossible to implement existing SMAs. This material will contribute to innovative developments of these cryogenic technologies as well as the downsizing or simplification of various cryogenic systems.

\section{CONFLICT OF INTEREST}

The authors declare no conflict of interest.

\section{ACKNOWLEDGEMENTS}

This study was supported by JSPS KAKENHI Grant Numbers JP22226011 and JP12J07777.

Author contributions: R.K. supervised the study. K.N. and Y.K. performed the experiments. K.N. analyzed the data. K.N. and R.K. wrote the manuscript. T.O. contributed to the discussion of the results.

\section{PUBLISHER'S NOTE}

Springer Nature remains neutral with regard to jurisdictional claims in published maps and institutional affiliations.

1 Otsuka, K. \& Wayman, C. M. in Shape Memory Materials (eds Otsuka K. \& Wayman C. M.) 149 (Cambridge Univ. Press, Cambridge 1998).

2 Jani, J. M., Leary, M., Subic, A. \& Gibson, M. A. A review of shape memory alloy research, applications and opportunities. Mater. Des 56, 1078-1113 (2014).

3 Humbeeck, J. V. Non-medical applications of shape memory alloys. Mater. Sci. Eng. A 273-275, 134-148 (1999).

4 Bonnot, E., Romero, R., Mañosa, L., Vives, E. \& Planes, A. Elastocaloric effect associated with the martensitic transition in shape-memory alloys. Phys. Rev. Lett. 100, 125901 (2008)

5 Nye, J. F. Physical Properties of Crystals, Oxford University: New York, (1957).

6 Wollants, P., De Bonte, M. \& Roos, J. R. Thermodynamic analysis of the stress-induced martensitic-transformation in a single-crystal. Z. Metallk. 70, 113-117 (1979).

7 Suzuki, Y. \& Tamura, H. in Engineering Aspects of Shape Memory Alloys (eds Duerig, T. W., Melton, K. N., Stockel, D. \& Wayman, C. M.) (Butterworth-Heineman, London, 1990).

8 Stachowiak, G. B. \& McCormick, P. G. Shape memory behaviour associated with the R and martensitic transformations in a NiTi alloy. Acta Metall. 36, 291-297 (1988).

9 Tanaka, Y., Himuro, Y., Kainuma, R., Sutou, Y., Omori, T. \& Ishida, K. Ferrous polycrystalline shape-memory alloy showing huge superelasticity. Science 327, 1488-1490 (2010).

10 Zarnetta, R., Takahashi, R., Young, M. L., Savan, A., Furuya, Y., Thienhaus, S. Maaß, B., Rahim, M., Frenzel, J., Brunken, H., Chu, Y. S., Srivastava, V., James, R. D., Takeuchi, I., Eggeler, G. \& Ludwig, L. Identification of quaternary shape memory alloys with near-zero thermal hysteresis and unprecedented functional stability. Adv. Funct. Mater. 20, 1917-1923 (2010)

11 Song, Y., Chen, X., Dabade, V., Shield, T. W. \& James, R. D. Enhanced reversibility and unusual microstructure of a phase-transforming material. Nature 502, 85-88 (2013).

12 Chluba, C., Ge, W., de Miranda, R. L, Strobel, J., Kienle, L., Quandt, E. \& Wuttig, M. Ultralow-fatigue shape memory alloy films. Science 348, 1004-1007 (2015).

13 Cui, J., Chu, Y. S., Famodu, O. O., Furuya, Y., Hattrick-Simpers, J., James, R. D., Ludwig, A., Thienhaus, S., Wuttig, M., Zhang, Z. \& Takeuchi, I. Combinatorial search of thermoelastic shape-memory alloys with extremely small hysteresis width. Nat. Mater. 5, 286-290 (2006).

14 James, R. D. Design of Supercompatible Shape Memory Alloys. Presented at the International Conference on Shape Memory and Superelastic Technologies (SMST 2017) (ASM International, San Diego, CA, 2017).

15 Sutou, Y., Omori, T., Yamauchi, K., Ono, N., Kainuma, R. \& Ishida, K. Effect of grain size and texture on pseudoelasticity in $\mathrm{Cu}-\mathrm{Al}-\mathrm{Mn}$-based shape memory wire. Acta Mater. 53, 4121-4133 (2005).

16 Liu, J., Huang, H. \& Xie, J. Superelastic anisotropy characteristics of columnar-grained $\mathrm{Cu}-\mathrm{Al}-\mathrm{Mn}$ shape memory alloys and its potential applications. Mater. Des. 85, 211-220 (2015).

$17 \mathrm{Ma}$, J., Karaman, I. \& Noebe, R. D. High temperature shape memory alloys. Int. Mater Rev. 55, 257-315 (2013).

18 Nikolaev, V. I., Pul'nev, S. A., Malygin, G. A., Shpeizman, V. V. \& Nikanorov, S. P. Pseudoelastic deformation and generation of reactive stresses in a Cu-Al-Ni shape-memory alloy in the temperature range 4.2-293 K. Phys. Sol. Stat. 49, 1878-1883 (2007).

19 Niitsu, K., Omori, T. \& Kainuma, R. Stress-induced transformation behaviors at low temperatures in Ti-51.8Ni (at. \%) shape memory alloy. Appl. Phys. Lett. 102, 231915 (2013).

20 Niitsu, K., Kimura, Y. \& Kainuma, R. Transformation entropy change and precursor phenomena in Ni-rich Ti-Ni shape memory alloys. J. Mater. Res 32, 3822-3830 (2017).

21 Niitsu, K., Xu, X., Umetsu, R. Y. \& Kainuma, R. Stress-induced transformations at low temperatures in a $\mathrm{Ni}_{45} \mathrm{C}_{5} \mathrm{Mn}_{36} \mathrm{In}_{14}$ metamagnetic shape memory alloy. Appl. Phys. Lett. 103, 242406 (2013).

22 Forrest, J. A. \& Dalnoki-Veress, K. The glass transition in thin polymer films. Adv. Colloid Interface Sci. 94, 167-196 (2001).

23 Yano, O. \& Yamaoka, H. Cryogenic properties of polymers. Prog. Polym. Sci. 20, 585-613 (1995).

24 Fujii, H., Yamamoto, A., Yabumoto, M., Ogata, T., Hayashi, M., Saito, M., Okaguchi, S., Wada, Y. \& Nakagawa, H. in Evaluation of Mechanical Properties of Austenitic Stainless 
Steels and Aluminium Alloy in Liquid Hydrogen. Hydrogen Energy Progress XII (Proc. of 12th World Hydrogen Energy Conference) (eds Bolcich, J. C. \& Veziroglu, T. N.) 1893-1902 (Corradi Impressiones, Buenos Aires, Argentina, 1998).

25 Ogata, T., Ishikawa, K. \& Nagai, K. Effects of strain rate on the tensile behavior of stainless steels, copper, and an aluminum alloy at cryogenic temperatures. Tetsu-to-Hagane 71, 1390-1397 (1985) (in Japanese).

26 Omori, T., Kusama, T., Kawata, S., Ohnuma, I., Sutou, Y., Araki, Y., Ishida, K. \& Kainuma, R. Abnormal grain growth induced by cyclic heat treatment. Science 341 , 1500-1502 (2013).

27 Kainuma, R., Takahashi, S. \& Ishida, K. Thermoelastic martensite and shape memory effect in ductile Cu-Al-Mn alloys. Metall. Mater. Trans. A 27, 2187-2195 (1996).

28 Kainuma, R., Takahashi, S. \& Ishida, K. Ductile shape memory alloys of the Cu-Al-Mn system. J. Phys. IV France A 05, 961-966 (1995).

29 Sutou, Y., Omori, T., Kainuma, R., Ono, N. \& Ishida, K. Enhancement of superelasticity in Cu-Al-Mn-Ni shape-memory alloys by texture control. Metall. Mater. Trans. A 33, 2817-2824 (2002)

30 Niitsu, K., Omori, T. \& Kainuma, R. Superelasticity at low temperatures in Cu-17Al-15Mn (at\%) shape memory alloy. Mater. Trans. 52, 1713-1715 (2011).

31 Xu, S., Huang, H.-Y., Xie, J., Takekawa, S., Xu, X., Omori, T. \& Kainuma, R. Giant elastocaloric effect covering wide temperature range in columnar-grained Cu71.5Al17.5Mn11 shape memory alloy. APL Mater. 4, 106106 (2016).

32 Marcos, J., Planes, A., Mañosa, L., Labarta, A. \& Hattink, B. J. Martensitic transition and magnetoresistance in a Cu-Al-Mn shape-memory alloy: influence of ageing. Phys. Rev. B 66, 054428 (2002).

33 Prado, M. O., Decorte, P. M. \& Lovey, F. Martensitic transformation in Cu-Al-Mn alloys. Scr. Metall. Mater. 33, 877-883 (1995).

34 Omori, T., Ando, K., Okano, M., Xu, X., Tanaka, Y., Ohnuma, I., Kainuma, R. \& Ishida, K. Superelastic effect in polycrystalline ferrous alloys. Science 333 , 68-71 (2011).
35 Mañosa, L., Jarque-Farnos, S., Vives, E. \& Planes, A. Large temperature span and giant refrigerant capacity in elastocaloric Cu-Zn-Al shape memory alloys. Appl. Phys. Lett. 103, 211904 (2013).

36 Brown, L. C. The thermal effect in pseudoelastic single crystals of $\beta$-CuZnSn. Metall. Trans. A 12, 1491-1494 (1981).

37 Rodriguez, C. \& Brown, L. C. The thermal effect due to stress-induced martensite formation in B-CuAINi single crystals. Metall. Mater. Trans. A 11, 147-150 (1980).

38 Lewandowski, J. J. \& Greer, A. L. Temperature rise at shear bands in metallic glasses. Nat. Mater. 5, 15-18 (2006).

39 Qian, S., Nasuta, D., Rhoads, A., Wang, Y., Geng, Y., Hwang, Y., Radermacher, R. \& Takeuchi, I. Not-in-kind cooling technologies: a quantitative comparison of refrigerants and system performance. Int. J. Refrigeration 62, 177-192 (2016).

(c) (i) This work is licensed under a Creative Commons Attribution 4.0 International License. The images or other third party material in this article are included in the article's Creative Commons license, unless indicated otherwise in the credit line; if the material is not included under the Creative Commons license, users will need to obtain permission from the license holder to reproduce the material. To view a copy of this license, visit http:// creativecommons.org/licenses/by/4.0/

(C) The Author(s) 2018

Supplementary Information accompanies the paper on the NPG Asia Materials website (http://www.nature.com/am) 